\title{
THIRD LEVEL DALAM FAKTOR KERANGKA KONSEPTUAL AKUNTANSI KEUANGAN
}

\author{
Rizqy Fadhlina Putri ${ }^{1}$, Rini Fadhillah Putri ${ }^{2}$ \\ Universitas Muslim Nusantara Al Washliyah \\ Email : rizqy.fadhlinaputri@gmail.com \\ Email : rinifadhillah25@gmail.com
}

\begin{abstract}
Abstrak
Tujuan penulisan ini adalah untuk mendeskripsikan faktor-faktor yang mempengaruhi kerangka kerja konseptual dalam akuntansi keuangan, sehingga diketahui dengan apakah factor utama dalam melaksanakan kerja yang tepat bagi calon akuntan, berdasarkan observasi $65 \%$ mahasiswa yang kurang memahami dengan baik kerangka konseptual. Sampel yang digunakan adalah mahasiswamahasiwa semester VI program studi Akuntansi Tahun Ajaran 2018/2019 Universitas Muslim Nusantara (UMN) Al Washliyah, diambil secara purposive sampling sebanyak 40 mahasiswa. Metode yang digunakan adalah kuantitatif, dengan demikian teknik analisa datanya adalah regresi linier yang dipertegas dengan analisis factor menggunakan IBM SPSS 22 for windows. Berdasarkan analisis yang dilakukan maka diperoleh bahwa yang menjadi factor yang mempengaruhi mahasiswa dalam kerangka kerja konseptual untuk akuntansi keuangan third level. Hal ini menjelaskan bahwa mahasiswa akuntansi kurang memahami third level pada kerangka konseptual akuntansi keuangan. Dengan diperlukan rekomendasi pelatihan serta pengayaan materi diluar kelas, sehingga membantu menjadikan mahasiswa unggul dan berkualitas .
\end{abstract}

Kata kunci: kerangka konseptual, akuntansi keuangan, third level

\begin{abstract}
The purpose of this paper is to describe the factors that influence the conceptual framework in financial accounting, so that it is known whether the main factors in carrying out the right work for prospective accountants, based on observations of $65 \%$ of students who do not understand well the conceptual framework. The sample used was the sixth semester students of the Accounting study program 2018/2019 Academic Year of the Muslim Nusantara University (UMN) Al Washliyah, taken by purposive sampling as many as 40 students. The method used is quantitative, so the data analysis technique is linear regression which is confirmed by factor analysis using IBM SPSS 22 for windows. Based on the analysis, it was found that the factors that influence students in the conceptual framework for third-level financial accounting. This explains that accounting students do not understand the third level of the conceptual framework of financial accounting. With the necessary training recommendations and enrichment of material outside the classroom, it helps to make students to become superior and qualified.
\end{abstract}

Keywords: conceptual framework, financial accounting, third level

\section{PENDAHULUAN}

Perkembangan teknologi dan pendidikan saat ini, sangat mempengaruhi setiap kalangan, terutama dalam dunia akuntansi. Sejak tahun 2015 hingga 2018, akuntan menjadi salah satu profesi dibutuhkan dalam setiap instansi. Kebutuhan akuntan ditunjukkan dengan kemampuan dalam pelaporan keuangan, sampai saat banyak perbaikan dan pengembangan dilakukan. Ikatan Akuntan Indonesia (IAI) yang telah mengembangkan kerangka konseptual yang akan dilakukan, perbaikan terakhir yang dilakukan pada tahun 2016 melalui exposure draft, dengan tujuan untuk meminta tanggapan atas seluruh pengaturan, artinya akuntan Indonesia 
menyelesaikan setiap keuangan sesuai dengan ketentuan yang berlaku.

Booth (2008:310) dan Bradbury (2008:388) mengemukan adopsi kerangka konseptual,setiap kerja tidak akan mengarah pada standar akuntansi yang konsisten, dan mau tidak mau kerangka kerja konseptual akan kurang kredibilitas selama tidak konsisten dengan undangundang dan mampu mengikuti secara International. Craig et all (2015:200) menegaskan bahwa kerangka konseptual harus dimasukkan dalam literatur otoritatif sebagai otoritas tertinggi, dan bahwa hal itu didasarkan pada kebutuhan pengguna dan prinsip-prinsip etis yang terkait dengan memenuhi kebutuhan tersebut. Lebih lanjut, dengan merekomendasikan adopsi kekhawatiran yang mengesampingkan untuk objektivitas dan ketidakberpihakan dalam membantu pengadilan untuk memahami hal - hal akuntansi yang rumit dalam kerangka konseptual. Peragamannya pendapat Sutton et.all (2015:116), mengemukan bahwa kepatuhan standar seharusnya tidak memberikan dasar untuk mengkompromikan representasi realitas ekonomi yang setia, anggapan mendukung akuntansi nilai wajar, mundur dari aset /pendekatan kewajiban.

Dari penjelasan ini, menegaskan bahwa kerangka konseptual harus dipahami oleh setiap akuntan. Walau Dean (2008:279) menegaskan bahwa tidak perlu ada dilakuakn pelatihan yang detail, untuk menyelesaikan keuangan sesuai dengan kerangka konseptual, Barth (2015:499) memaparkan hal yang berbeda bahwa ekonomi dan keuangan telah memberikan perspektif barudan wawasan yang berarti tentang informasi yang dibutuhkan investormembuat keputusan berdasarkan informasi. Apapun, ada banyak yang menarik dan terbukapertanyaan menunggu penelitian akuntansi yang dapat memberikan wawasan tentang bagaimanaakuntansi keuangan - dan dengan demikian akuntabilitas keuangan — dapat ditingkatkan. Penjelasan tersebut menegaskan bahwa kerang konseptual merupakan kegiatan untuk memberikan informasi keuangan, yang disusun dalam kerangka baku sehingga mudah dalam menyamakan isi informasi keuangan, Indonesia telah banyak mengupayakan mengembangkan peraturan-peraturan dalam menyelesaikan setiap informasi, sehingga informasi yang disampaikan benar dan tepat. Akuntan Indonesia harus memahami dalam melaksanakannya, sehingga mengurangi kecurangan keuangan Negara.

Pentingnya kerangka konseptual, diberikan kepada setiap mahasiswa akuntansi, sehingga siap menyelesaikan kerangka konseptual sesuai tujuan pembelajaran yaitu memahami kerangka konseptual akuntansi sektor publik dan standar akuntansi sektor publik. Berdasarkan observasi yang dilakukan, mahasiswa masih kesulitan dalam mengikuti pembelajaran kerangka konseptual. Tes yang dilakukan diketahui bahwa mahasiswa kurang memahami menyelesaikan keuangan sebesar $65 \%$, artinya mahasiswa belum siap menerima penyelesaian kerangka konseptual sesuai standar akuntan yang telah ditetapkan oleh pemerintah. Wawancara dengan mahasiswa diketahui banyaknya aturan yang berlaku dalam informasi laporan mengakibatkan mahasiswa kebingungan dalam hal-hal yang harus ditetapkan dalam third level. Mahasiswa menyatakan didalam kelas bahwa terlalu banyak aturan yang harus dihapal dan dipahami terutama pada factor asumsi, prinsip, kendala, karakteristik kualitatif dan elemen, sehingga menarik untuk dideskripsikan faktor kerangka konseptual yang harus diperbaiki.

Tujuan penulisan ini adalah untuk mendeskripsikan factor yang mempengaruhi kerangka konseptual dalam akuntansi keuangan.

\section{METODE}

Lokasi penelitian dilaksanakan di Fakultas Ekonomi Program Studi Akuntansi Universitas Muslim Nusantara 
(UMN) AL Washliyah Medan. Jenis data yang digunakan adalah data primer, dengan membagikan angket berskala Likert kepada responden yang telah ditentukan. Menurut Sugiono (2010:15) “ Populasi adalah wilayah generalisasi yang terdiri atas objek atau subjek yang mempunyai kualitas dan karakteristik tertentu yang ditetapkan oleh peneliti untuk dipelajari dan kemudian ditarik kesimpulan. Populasi dalam penelitian ini adalah seluruh mahasiswa semester 6 Program Studi Akuntansi Fakultas Ekonomi Tahun Ajaran 2018/2019. Dalam penelitian ini sampel yang akan diambil secara conveniencesampling, hal ini sebabkan karena menurut Gunawan (2013:9) pengambilan sampel dilakukan berdasarkan kemudahan mendapatkan data yang diperlukan, maka sampel yang terlibat adalah 40 mahasiswa akuntansi.

Metode kuesioner (angket) yaitu sejumlah pertanyaan tertulis yang digunakan untuk memperoleh dari responden dalam arti laporan pribadinya atau hal yang diketahui. Atau teknik pengumpulan data dengan menyusun daftar pertanyaan atau pernyataan tertulis yang diajukan kepada responden sample yang akan diteliti. Jumlah pertanyaan yang akan diambil berdasarkan variabel penelitian, baik variabel dependen dan varoabel independen. Kuesioner diberikan kepada langsung responden dengan tujuan agar lebih efektif dan efisiensi dalam menjangkau jumlah sample dan lebih muda dalam menjelaskan angket.Intrusmen yang digunakan dalam mengukur variabel penelitian ini dengan menggunakan skala likert dengan 5 poin jawaban responden.

Uji analisa data yang digunakan adalah regresi linier sederhana. Regresi linier adalah uji yang digunakan untuk mengetahui pengaruh antara variabel independen terhadap variabel dependen. Untuk menguji dilakukan dengan menggunakan SPSS IBM 22 for windows. Sesuai dengan satu variabel indpenden yang terdiri dari variabel yaitu third level $(\mathrm{X})$ dan satu variabel dependen (Y) yaitu kerangka konseptual akuntansi keuangan. Dalam penelitian ini menggunakan metode analisa berupa analisis faktor. Analisis faktor adalah analisis yang bertujuan mencari faktorfaktor utama yang paling mempengaruhi variabel dependen dari serangkaian uji yang digunakan atas serangkaian variabel independen sebagai faktornya. Ketika pembuatan matriks maka akan digunakan Barletts test sphericity dan Kiser-MayerOlkin (KMO) untuk mengetahui kecukupan sampelnya. Menurut Suliyanto (2005:2), diketahui ada kategori nilai KMO yaitu:

a. Nilai KMO sebesar 0,9 adalah baik sekali

b. Nilai KMO sebesar 0,8 adalah baik

c. Nilai KMO sbesar 0,7 adalah sedang

d. Nilai KMO sebesar 0,6 adalah cukup

e. Nilai KMO sebesar 0,5 adalah kurang

f. Nilai KMO kurang dari 0,5 adalah ditolak

Dalam penentuan jumlah faktor yang ditentukan untuk mewakili variabelvariabel yang akan dianalisis didasarkan pada besarnya eigenvalue serta persentase total variannya, hanya faktor yang memiliki eigenvalue sama atau lebih besar dari satu yang dipertahankan dalam model analisis faktor, kemudian akan dianalisis dengan mengektraksi faktor dalam matriks faktor mengidentifikasi hubungan antar faktor dan variabel individual, sehingga matriks ditransformasikan kedalam matriks yang lebih sederhana dengan menggunakan prosedur varimax. Selanjutnya dilanjutkan dengan interprestasikan faktor dengan mengklasifikasikan variabel yang mempunyai factor loading minimum 0,4 sedangkan variabel dengan factor loading kurang dari 0,4 dikeluarkan dari model.

\section{HASIL DAN PEMBAHASAN}

Analisis regresi linier ganda digunakan untuk mengetahui hubungan atau pengaruh antara variabel bebas (X) yaitu third level dan satu variabel 
dependen (Y)yang ditampilkan dalam bentuk persamaan regresi, yaitu:

a. third level $\left(\mathrm{X}_{3}\right)$, diperoleh nilai $\mathrm{b}$ sebesar 0,279

b. nilai a diperoleh sebesar 15,286

Dengan demikian persamaan regresi linier berganda dapat diketahui sebagai berikut:

$$
\begin{gathered}
\mathrm{Y}=a+b \\
\mathrm{Y}=15,286+0,279 X
\end{gathered}
$$

Kerangka Konseptual $=15,286+0,279$ thrid level

Dengan demikian dapat dijelaskan bahwa besarnya nilai konstanta (a) 15,286 menjelaskan bahwa variabel independen dianggap konstan, maka rata-rata kerangka konseptual akuntansi keuangan sebanyak 15,286 pemahaman atau 15 responden, kemudian nilai koefisien regresi untuk setiap penambahan pemahaman kerangka konseptual akan meningkatkan pemahaman sebanyak 0,470 atau 0,5 dan third level sebanyak 0,279 artinya third level akan menambahkan pemahaman kerangka konseptual.

Persamaan regresi linier ganda, uji akan dilanjutkan dengan uji t digunakan digunakan untuk mengetahui apakah variabel independen secara individu berpengaruh terhadap variabel dependen. Adapun ketentuan penerimaan atau penolakan pengujian ini yaitu apabila angka signifikan kurang dari 0,05 maka hipotesis alternatif diterima dan hipotesis nol ditolak. Pengujian hipotesis juga dapat dilakukan dengan menggunakan perbandingan antara thitung dengan ttabel dengan ketentuan: Jika sig $<0,05$, maka Ho ditolak (ada pengaruh yang signifikan) dan Jika sig > 0,05, maka Ho diterima (tidak ada pengaruh yang signifikan). Hasil yang diketahui bahwa: nilai sig $<0,05$ yaitu $0,000<0,05$ diketahui bahwa thrid level dapat mempengaruhi kerangka konseptual akuntansi keuangan

Analisis faktor lebih merupakan teknik statistik multivariate yang dimulai dengan pengujian variabel-variabel yang bisa dilakukan proses factoring, melakukan ekstraksi variabel, rotasi jika diperlukan dan diakhiri dengan penamaan faktor. Dalam hal ini juga digunakan untuk mengurangu (reduction) dan meringkas (summarization) semua vaiabel terikat dan saling ketergantungan. Dari hasil SPSS untuk data hasil kusioner.

Nilai KMO dan Barlett's test untuk korelasi antarvariabel yang diinginkan lebih besar dari 0,5 (>0,5) dan signifikan penelitian adalah 0,05. Dari hasil diatas diperoleh KMO sebesar 0,773, sesuai dengan kategori metode bahwa 0,773 berada pada kategori sedang dan lebih besar dari 0,5 , sementara signifikan yang dihasilkan Barlett's test of Sphericity sebesar 0,001. Dengan demikian, dapat dikatakan variabel dan sampel yang digunakan memungkinkan untuk dilakukan analisis lebih lanjut. Selanjutnya, untuk melihat korelasi antarvariabel independen dapat diperlihatkan pada tabel Anti-Image Matrics. Nilai yang diperhatikan adalah MSA (Measure of Sampling Adequacy). Nilai MSA berkisar 0 hingga 1, dengan ketentuan sebagai berikut:

- MSA $=1$, variabel dapat diprediksi tanpa kesalahan oleh variabel lain

- MSA > 0,5 variabel masih bisa diprediksi dan bisa dianalisis lanjut

- MSA < 0,5 varabel tidak bisa diprediksi dan tidak bisa dianalisis

Dari hasil output di atas, diketahui bahwa nilai MSA, maka diperoleh hasil sebagai berikut:

- Thrid Level : 0,945 > 0,5

Berdasarkan hasil MSA diatas, diketahui bahwa seluruh variabel independen dapat dianalisis lebih lanjut karena masingmasing masih dalam ketentuan yaitu masih bisa diprediksi.

Dari hasil diatas diketahui faktor mampu menjelaskan variabel third level sebesar 0,711 atau $71,1 \%$, sehingga dapat disimpulkan rata-rata penjelasan diatas $50 \%$ maka faktor akan tetap akan ditentukan. 
Dilanjutkan dengan "inti" dari analisis faktor konfirmatori, guna menentukan seberapa banyak faktor yang mungkin terbentuk

Diketahui bahwa component berkisar antara 1 hingga 4 atau dengan kata seluruh variabel independen terwakili. Dengan memperhatikan kolom Initial Eigenvalues dengan SPSS dengan menentukan nilainya 1 . Varians yang bisa diterangkan oleh faktor 1 sebesar 3,087/4 x $100 \%=77,176$. Dengan demikian, karena Initial Eigenvalues yang ditetapkan 1 maka nilai total yang akan diambil adalah yang lebih dari 1 ( > 1) yaitu component 1 .

Dalam hal ini diketahui dengan jelas, bahwa mahasiswa kurang memahami pada bagian third level yang berkaitan dengan asumsi, prinsip dan kendala. Berdasarkan hasil belajar yang telah dikerjakan mahasiswa melaui laporan keungan. Pada bagian third level mahasiswa masih kurang paham dalam menyelesaikan permasalahan laporan keuangan. Pada third level mahasiswa pada penilaian asumsi dan prinsip, mahasiwa tidak mampu menemukan cara yang tepat dalam mengikuti aturan pada kerangka konseptual yang telah ditetapkan.

Hasil perolehan yang telah dikemukan, dibutuhkan rekomendasi untuk memberikan pelatihan dan banyaknya aturan yang diberikan kepada mahasiswa mempersulit menyelesaikan laporan keuangan. Kerangka konsep yang telah ditetapkan oleh IAI melalui peraturan mengekang dalam menentukan komponen laporan yang akan diselesaikan.

Hal ini sesuai dengan hasil penelitian terlebih dahulu oleh Ahmed (2018:1) pendekatan dapat membantu mengatasi kekurangan metodologis dalam mengukur kinerja etisdalam keuangan Islam dengan berfokus pada proses pengambilan keputusan etis yang mengarah pada hasilperilaku organisasi di luar legalitas kontrak. Kerangka kerja ini menguraikan kondisidi mana suatu kegiatan yang dianggap sah dan diizinkan secara kontraktual dapat memimpinuntuk hasil yang dapat membuatnya etis atau tidak etis, artinya sama hal dengan hasil yang diperoleh, mahasiswa harus disesuaikan dengan kondisi dan kebiasaan dalam mengerjakannya.

\section{KESIMPULAN}

Berdasarkan hasil yang diperoleh, maka diketahui simpulan sebagai berikut:

1. $\mathrm{H}_{\mathrm{a}}$ diterima bahwa ada pengaruh third level $\left(\mathrm{X}_{3}\right)$ terhadap kerangkan konseptual akuntansi keuangan

2. Third level merupakan faktor yang paling dominan dalam kerangka konseptual akuntasi keuangan,

\section{DAFTAR PUSTAKA}

Alziadat, Ahmed., Ethical decision-making in Islamic financial institutions in lightof Maqasid Al-Sharia: A conceptual framework. 2008:2

Barth, 2015. Financial Accounting Research, Practice, andFinancial Accountability. ABACUS Journal Accounting Foundation, The University of Sydney, 51 (4):499\&503

Booth, (2008). The Conceptual Framework as aCoherent System for the Developmentof Accounting Standards. ABACUS Journal Accounting Foundation, The University of Sydney, 39 (3):301

Badury., (2008). Implications for the ConceptualFramework Arising From Accountingfor Financial Instruments.ABACUS Journal Accounting Foundation, The University of Sydney, 39 (3):388

Craig, Smieliauskas and Amernic, (2014). Assessing Conformity with Generally Accepted AccountingPrinciples Using Expert Accounting Witness Evidence and the Conceptual Framework. 27 (4): 200

Dean and Clarke, (2008). An Evolving Conceptual Framework?. ABACUS 
Journal Accounting Foundation, The University of Sydney, 39 (3):279

Ghozali., (2013). Aplikasi Analisis Multivariate dengan Program IBM SPSS 21 Update PLS Regresi. Penerbit Universitas Diponegoro. Semaran

IAI., 2016. Kerangka Dasar SAK Umum. http://iaiglobal.or.id/v03/standarakuntansi-keuangan/tentang-5kerangka-dasar-sak-umum

Kurniawan., (2014). Conceptual Framework For Financial Reporting (Rerangka Konseptual Pelaporan Keuangan). 2008:1

Sugiono., (2010). Metode Penelitian Kuantitatif, Kualitatif dan $R \& D$. Penerbit Alfabeta. Bandung

Sutton, Cordery, And Zijl., (2015). The Purpose of Financial Reporting: TheCase for Coherence in the ConceptualFramework and Standards. ABACUS Journal Accounting Foundation, The University of Sydney, 51(1):116 